\title{
Percepção ambiental acerca do Chrysocyon brachyurus (Lobo-Guará) no município Guaraí (TO)
}

O Chrysocyon brachyurus, conhecido popularmente como Lobo-guará, é um dos canídeos mais exuberantes da fauna brasileira encontrado em todo o território do bioma cerrado. Atualmente está na lista de espécies ameaçadas de extinção segundo o IUCN devido a devastação do seu habitat, surgimento de doenças e lendas. Com grande importância local, o animal é responsável pelo nome do município de Guaraí, no Estado do TO, embora o crescimento urbano e das áreas agrícolas contribuíram para a drástica redução da estrutura populacional da espécie na região. Este trabalho teve como intuito buscar as raízes históricas do município Guaraí (TO) e seu vínculo com o Lobo-guará através de análises de percepções dos moradores do município. Adotou-se a abordagem fenomenológica para análise dos discursos e estatística descritiva por meio de entrevistas. Foi observado uma ligação entre os moradores do município de Guaraí e suas raízes históricas aliadas ao Lobo-guará, a construção de lendas locais passadas por gerações e a preocupação na preservação da espécie na região.

Palavras-chave: Chrysocyon brachyurus; Lobo-guará; Percepção Ambiental; Guaraí.

\section{Environmental perception about Chrysocyon brachyurus (Lobo- Guará) in the municipality of Guarai (TO)}

\begin{abstract}
The Chrysocyon brachyurus, popularly known as Lobo-guará, is one of the lushest canids of Brazilian fauna found throughout the territory of the Cerrado biome. It is currently on the list of IUCN threatened species due to the devastation of its habitat, the emergence of diseases and legends. With great local importance, the animal is responsible for the name of the municipality of Guaraí, in the state of OT, although urban and agricultural growth contributed to the drastic reduction of the population structure of the species in the region. This work aimed to search the historical roots of the municipality of Guarai (TO) and its link with the Loboguará through analyzes of the residents' perceptions of the municipality. We adopted the phenomenological approach for discourse analysis and descriptive research through interviews. It was observed a connection between the residents of the municipality of Guarai and their historical roots allied to Lobo-guará, the construction of local legends passed by generations and the concern in the preservation of the species in the region.
\end{abstract}

Keywords: Chrysocyon brachyurus; Guara wolf; Environmental Perception; Guaraí.

Topic: História Ambiental

Reviewed anonymously in the process of blind peer
Received: 06/02/2019

Approved: 11/05/2019
Ineide Ferreira Luz

Faculdade Guaraí, Brasil

ineideferreira10@hotmail.com

Jaciara Silva Sene

Faculdade Guaraí, Brasil

jacy7sene@gmail.com

Aluísio Vasconcelos de Carvalho (id

Faculdade Guaraí, Brasil

http://lattes.cnpq.br/5200758055263996

http://orcid.org/0000-0002-3793-3133

aluisiovasconcelos@gmail.com

\section{Referencing this:}

LUZ, I. F.; SENE, J. S.; CARVALHO, A. V.. Percepção ambiental acerca do Chrysocyon brachyurus (Lobo-Guará) no município Guaraí (TO) Humanum Sciences, v.1, n.1, p.1-10, 2019. DOI: http://doi.org/10.6008/CBPC2674-6654.2019.001.0001
DOI: 10.6008/CBPC2674-6654.2019.001.0001 


\section{INTRODUÇÃO}

O Chrysocyon brachyurus, conhecido popularmente como Lobo-guará, Aguara-guazu, Lobo de Juba, ou simplesmente Guará, são as nominações atribuídas à espécie que significa Cão-dourado-de-cauda-curta (PRATES JÚNIOR, 2008; FARIA, 2013). Segundo Sousa (2000), é considerado um dos canídeos mais belos e elegantes da América do Sul.

Para Terborgh (1992), a espécie é um elemento fundamental para o ecossistema, pois dentre os mamíferos, os carnívoros são controladores de populações de suas presas, contribuindo para a dispersão de sementes e influenciando na diversidade da comunidade.

O Chrysocyon brachyurus é considerado um animal vulnerável ao risco de extinção por estar exposto a constantes ameaças (PAULA et al., 2008; ICMBIO, 2009; IUCN, 2000; MACHADO et al., 2008). De acordo com o Instituto Chico Mendes de Conservação da Biodiversidade-ICMBIO (2009), os principais problemas do desaparecimento do Lobo-guará são devido à devastação do cerrado, principal habitat do animal, e o desenvolvimento socioeconômico no Brasil. Dentre estes, também contribuem para esse resultado, os confinamentos em cativeiros, reservas mal administradas, ambiente natural invadido pelas atividades antrópicas, distúrbios do aparelho digestório e respiratório, acidentes, lesões, contato com animais domésticos como cães, que favorece a infecção de doenças como cinomose, parvovirose, raiva, leptospirose, hepatite, encefalite, entre outros, contribuem para a redução populacional desse canídeo (COSTA, 1967; MAIA et al., 2002).

Atualmente, observa-se que no município de Guaraí (TO), a presença do Lobo-guará vem se tornando cada vez mais rara devido as constantes alterações do ambiente reduzindo as populações naturais na região aliado a cultura local passada de geração por meio de lendas e mitos, muito comum em populações tradicionais do cerrado que convivem ou tiveram experiência com a espécie (ICMBIO, 2009; ANIC, 2002).

Com grande influência histórica no município de Guaraí, o animal evidencia sua importância nesse estudo por se tratar de uma peça primordial no processo de identidade municipal. Segundo a Prefeitura Municipal de Guaraí (2017) e Halum (2008) o município teve início com um povoado chamado "Guará”, logo se municipalizou com o nome de "Guarai", que significa "lobo pequeno" ou "rio dos guarás" na língua indígena tupi influenciado pela grande quantidade de espécimes existentes na região, sendo assim o principal responsável pela nomeação do município.

De acordo com Melo (2013) existe uma relação tênue de motivação que interligam a origem do nome e seu significado ao lugar, o que denota não ser totalmente arbitrário. Estudos topônimos tem a finalidade de investigar a origem dos nomes dos lugares a partir dos significados e transformações que o moldaram (ROSTAING, 1961).

Tal ciência está conjugada com a história mostrando em seus relatos os traços linguísticos de um grupo ou região, migração, colonização, dentre outros comportamentos que denota os atributos do lugar ou local (DAUZAT, 1926). Caracterizado pela herança amazônica, os nomes tocantinenses quase sempre assumem uma relação com a fauna local ou característica da água (FERRAZ et al., 1999). 
Este trabalho tem como intuito buscar as raízes históricas do município Guaraí (TO) e seu vínculo com o Lobo-guará através de análises de percepções dos moradores do município.

\section{METODOLOGIA}

\section{Área de coleta dos dados}

A pesquisa social foi realizada no Município de Guaraí, localizada a $178 \mathrm{Km}$ da capital do Estado do

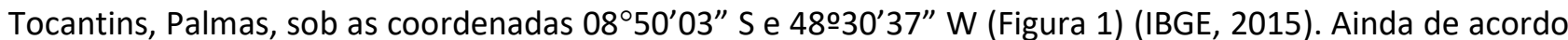
com dados publicados pelo Instituto Brasileiro de Geografia e Estatística, o município de Guaraí encontra-se na região Ocidental do Tocantins e sua microrregião é a de Miracema do Tocantins, com uma população estimada de 25.149 habitantes. Predomina-se o domínio do cerrado (COUTINHO, 2006; AB'SABER, 2003), possui um clima tropical com classificação do tipo AW (KÖPPEN, 1931) possuindo altas temperaturas variando entre 18ㅇ C e 36 o C dividido em um verão chuvoso, que dura de outubro a meados de abril e um inverno seco, com chuvas bem raras de maio a setembro (IBGE, 2015).

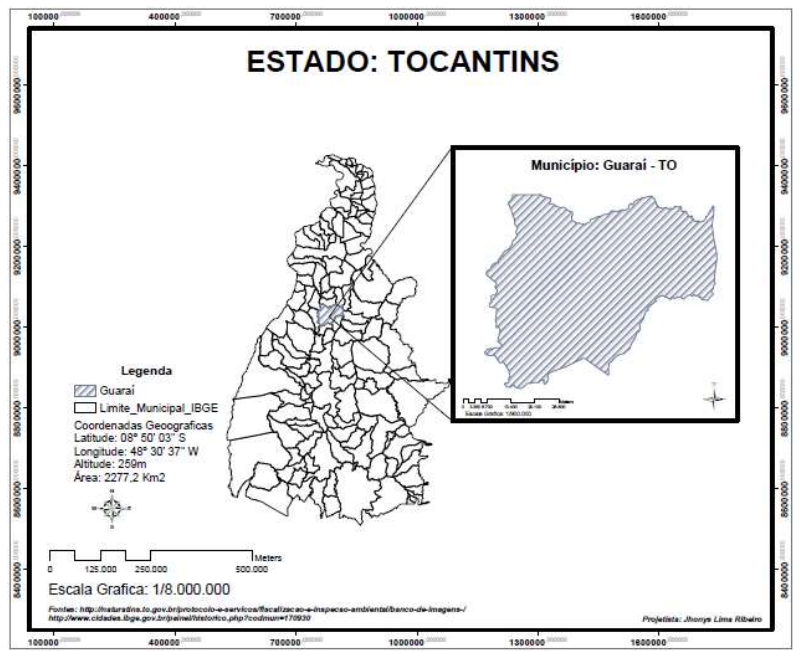

Figura 1: Mapa do Tocantins dando ênfase ao Município de Guaraí (TO). Fonte: IBGE, 2017

\section{Coleta de dados}

A pesquisa foi realizada em 4 etapas: Seleção da região a ser entrevistada, aplicação entrevista, tabulação dos dados e análise dos resultados da pesquisa (MARCONI et al., 2004). Durante a execução da pesquisa foram realizadas entrevistas com a população para investigar os fatores históricos que possivelmente levaram a diminuição da população natural de Lobo-guarás na região. O roteiro deve apresentar 3 características fundamentais, como se fosse a espinha dorsal de qualquer levantamento, onde deve se reunir todas as informações necessárias (nem mais nem menos) e possuir uma linguagem adequada e de fácil entendimento (OLIVEIRA et al., 2014; MOYSÉS et al., 2007).

Foram definidos critérios para serem aplicados nas entrevistas, pessoas maiores de 18 anos com residência fixa no município ou região e que sejam conhecedores dos dados históricos que permeiam o município de Guaraí (TO). Foi entregue primeiramente um termo de livre esclarecimento ao entrevistado, para que a entrevista ocorresse de forma legal (GOLDIM, 2003), e logo após a entrega do questionário com 
perguntas relacionadas à história e as possíveis causas do desaparecimento do Lobo-guará no município e região.

As coletas de dados foram realizadas no período de 27 de janeiro a 22 de fevereiro de 2017, através do questionário semiestruturado com perguntas relacionadas ao objeto da pesquisa. As entrevistas compuseram-se de questões abertas, para o interlocutor expressar a sua opinião, e fechadas, com opções de múltipla escolha, evidenciando as várias facetas do mesmo assunto (MARCONI et al., 2004).

Para seleção dos entrevistados adotou-se a metodologia de amostragem bola de neve. Esse método funciona a partir da indicação por parte de algum indivíduo da população, e assim sucessivamente pelos interlocutores (DEWES, 2013).

\section{Tabulações de dados}

Os dados foram tratados através de estatística descritiva com resultados quantitativos e qualitativos. A pesquisa descritiva tem como intuito observar os fatos, registrar, analisar, classificar e interpretá-los, sem que ocorra a interferência do pesquisador (RODRIGUES, 2007). Para os enunciados relatados pelos entrevistados, utilizou-se a abordagem fenomenológica. Esta técnica inicia com uma descrição, uma circunstância vivida no dia a dia a partir das experiências dos interlocutores (GIORGI, 1986; SADALA, 2004).

Devido à natureza da pesquisa, houve a necessidade de utilizar a metodologia de White (1977), baseada estrategicamente em ouvir, perguntar e observar. De acordo com o mesmo autor, a metodologia aplicada tem como ponto de partida o procedimento ouvir, em que os interlocutores pudessem expressarse livremente acerca do assunto, revelando as suas percepções sem a influência dos pesquisadores, logo após partiu-se para o perguntar, direcionando as questões para o assunto pesquisado e observar, verificando o comportamento dos entrevistados ao longo da pesquisa.

\section{RESULTADOS E DISCUSSÃO}

\section{Perfil dos entrevistados}

Foram entrevistadas no total 31 indivíduos, de ambos os sexos e com diferentes idades. Dos 31 entrevistados, 51,6\% da amostra era masculina, com faixa etária entre 19 e 81 anos dos entrevistados de ambos os sexos. A maioria eram naturais do município de Guaraí (TO), com pelo menos 18 anos de residência na região.

A maior parte dos entrevistados na presente pesquisa, exerciam alguma atividade trabalhista, entre eles, agentes comunitários de saúde da zona rural e trabalhadores rurais, sendo na maioria, servidores públicos do município de Guaraí. Além disso, desenvolvem outras atividades para complementar a renda como a criação de animais e agricultura de subsistência, entre outras atividades. Estas características podem justificar os aspectos do desenvolvimento econômico e social do município e região, segundo o Instituto Brasileiro de Geografia e Estatística (2013), o município de Guaraí sofre influência da agropecuária, o que 
resulta nos altos índices do produto interno bruto (PIB), com cerca de 39.788 reais referente as atividades voltadas para agropecuária.

Marouelli (2003) afirma que existem várias consequências ocasionadas pelo crescimento agrícola de forma demasiada causando impactos ambientais como a erosão, a perda de fertilidade dos solos, a contaminação da água, entre outros, reduzindo os ambientes naturais. São inúmeras discussões relacionadas a crescente destruição dos recursos naturais do território brasileiro, atingindo alguns biomas característicos deste território, como Amazônia, a Mata Atlântica e o Cerrado (COUTINHO, 2006).

O Cerrado Tocantinense vem sofrendo fortes perturbações mediadas pelas monoculturas. De acordo com Cunha et al. (2008) a expansão da agricultura e pecuária tem contribuído para a perda de espécies endêmicas e da biomassa vegetal originária desse ambiente. A redução de tais espécies contribui para a entrada na lista vermelha de espécies ameaçadas de extinção ou vulneráveis, atualizada anualmente pela União Internacional para Conservação da Natureza- IUCN, como o Lobo-guará (MANTOVANI et al., 2007).

\section{Fatores históricos associados a Guaraí segundo os entrevistados}

Dentre os entrevistados, $87 \%$ afirmaram que a origem do nome do município Guaraí se deve a grande quantidade de Lobo-guará que existia na região. Já os outros $13 \%$ dos entrevistados opinaram que o nome do município se originou devido a criação da rodovia Belém-Brasília (BR-153), na qual corta o Município de Guaraí de norte a sul. Nenhum dos entrevistados aderiram a alternativa do nome do município ter sido em virtude a alguma tribo indígena. Suas populações foram reduzidas drasticamente por consequências da degradação do cerrado, alguns tipos predadores e o aumento das lavouras conforme a fala de alguns interlocutores.

O termo 'Guará' é usualmente utilizado para nomear três espécies brasileiras: o mamífero Chrysocyon brachyurus, vulgo Lobo-Guará, uma ave da espécie Eudocimus ruber e um peixe da família Carangidae (FERREIRA, 1996; CARVALHO, 1969). Uma característica marcante, a cor avermelhada, muitas vezes foi traduzida de maneira errônea, já que o termo guará derivado de guyrá, não representa comparação com a coloração do Eudocimus ruber nem mesmo reflete no cognato de aguará, forma corrupta de Jaguá, que indistintamente significa cachorro ou gato, forma redundante de Lobo-guará (STRAUBE, 1999).

Não obstante, a língua Tupi foi a língua que mais moldou e produziu nomes geográficos no território brasileiro, perdendo apenas para o português (NAVARRO, 2006). Essa característica se deu porque a língua Tupi era a mais falada na costa brasileira, índios, brancos e mamelucos a utilizaram como meio de comunicação por quase um século, o que facilitou no processo de desbravamento do país (MELO, 2013).

Do ponto de vista histórico, a construção da BR-153 contribuiu para a formação de cidades ao longo da rodovia. O perfil migratório regional é notoriamente nordestino (ARRAIS et al., 2016). De acordo com registros do censo demográfico de 1970, os Estados do Maranhão, Piauí e Ceará tiveram a maior participação do processo migratório regional nos municípios atravessados pela rodovia (IBGE, 1970). Esse percentual chegou a $40 \%$ em Guaraí e a 38\% em Paraíso (ARRAIS et al., 2016). Grande parte desses imigrantes eram oriundos de outras regiões, motivados pela posse de terras, na construção de fazendas, derrubadas de matas 
e aberturas de pastos. Por outro lado, algumas pessoas que foram contratadas pelas empresas responsáveis pela construção da rodovia, acabaram ficando na região formando grupos familiares ou abrindo comércios (MACHADO, 1979; HÉBETTE, 2015).

O crescimento urbano desordenado aliado às atividades agrícolas contribuiu para o declínio populacional de Lobos-guará, embora na época de formação urbanística havia grande quantidade de espécime na área, tal fato é registrado, segundo os interlocutores da presente pesquisa, a Fazenda Guará, primeiro aglomerado da região a receber o nome homenageando o animal, que mais tarde, tornou-se município à medida que o número de pessoas iam aumentando e se alojando no território onde se encontra a atual cidade. 0 processo de urbanização torna o Lobo-guará obrigado a entrar em contato com o homem, sendo caçados ou atropelados em rodovias (SOUSA, 2000; BOAS et al., 2015).

\section{Lendas Locais associados ao Lobo-guará segundo os entrevistados}

No decorrer da pesquisa algumas pessoas relataram histórias e lendas de grande interesse sobre o Lobo-guará, afirmando alguns fatos como "o animal ser um bicho azarado", "que come o feto de mulheres grávidas" e "gosta de comer o glúteo e as mamas das mulheres". Durante a aplicação do questionário, um dos entrevistados relatou uma lenda que:

Quando uma mulher ou um homem quer atrair uma pessoa, ela tem que matar o lobo, arrancar o olho e guardar sempre consigo dentro da carteira ou do bolço. Pois, com o fato de estar sempre com o olho, consegue o homem atrair a mulher e ela atrair o homem. Porém para conseguir atrair a mulher, tem que matar o lobo macho e arrancar o olho, e o homem tem que matar a loba fêmea, tendo isso sempre consigo, irá conquistar a mulher que ele deseja (I.P.S).

Para Otto (2007), o sagrado é apreendido por meio de experiências vividas pelos envolvidos que nos causa fascínio, hipnose, uma profunda devoção meditativa do todo outro. Os relatos dos moradores acerca do Lobo-guará remetem uma mentalidade dominante restrito a situações empíricas e demarcadas de geração em geração na construção do mito.

Estudos etnobiológicos, mais precisamente etnozoologia, tem contribuído para o entendimento de saberes tradicionais e conhecimentos científicos; os pescadores, ribeirinhos, indígenas, entre outros, possuem uma riqueza cultural que alimenta a cultura brasileira (MESQUITA, 2004). Segundo Diegues (1988), a conservação da biodiversidade dependerá da preservação dos conhecimentos culturais regionais. Segundo outro entrevistado:

O Lobo-guará é um animal azarado, pois se o matá-lo, quem o fez, terá muitas mortes na família (J.I.S)

Tais lendas, são levadas em grande consideração pela população, passadas entre as gerações, contribuindo assim para os fatos históricos tanto da cidade quanto no animal. Contudo, as crendices populares também podem gerar resultados contrários, já que elas podem acabar contribuindo para o abate do Lobo-guará (SILVA et al., 1994). Anic (2002) afirma que o desaparecimento das crendices populares é em virtude as pessoas estarem tendo mais acesso às informações, mas ainda podem contribuir para o desaparecimento do animal já que ainda há muitos relatos sobre a imagem negativa do Lobo-guará. 


\section{Percepção acerca da preservação dos canídeos da região}

Conforme a opinião dos entrevistados na pesquisa, $90 \%$ deles concordam com a preservação do Lobo-guará. Mesmo muitos sendo leigos sobre o termo extinção, foram aptos a sugestões que poderiam ser realizadas para evitar tal consequência, onde $12 \%$ sugeriram que a população deveria ser conscientizada a respeito da extinção, $22 \%$ relataram sobre a preservação do habitat do animal e $66 \%$ a necessidade de inserção de projetos de conservação na região.

Ainda perante a resposta dos mesmos entrevistados, cerca de $100 \%$ deles acharam que os estudos e o mapeamento do território do animal poderiam ajudar a conhecer melhor seus hábitos alimentares e a convivência do Lobo-guará na região. Os interlocutores afirmaram ainda que o animal não pode trazer consequências ruins para o ser humano e deve se fazer um levantamento da quantidade de animal ainda existente no território e ter fiscalização e monitoramento do animal.

Dentre os entrevistados, constatou-se que a maioria era consciente a respeito das causas que levaram a redução da população de Lobos-guarás na região, o que gerou grande expectativa a respeito da preservação deste animal. Segundo os entrevistados, as principais causas para esse resultado estão associadas a degradação do cerrado, alguns tipos de predadores e o aumento das lavouras.

Para Ribeiro et al. (2008), a caça predatória, o extrativismo e a produção agropecuária mal manejada são ações prejudiciais que deplecionam as populações naturais existentes na região. Segundo o mesmo autor, se o tema "agricultura ecológica" fosse mais ampliado e desenvolvido nos cursos universitários da área agronômica e ambiental, seria possível estabelecer um tripé de conhecimento e desenvolvimento sustentável.

Outra estratégia que poderia ser utilizada para minimizar os impactos ambientais, seria os corredores de habitat, também conhecido como corredor ecológico, que é conectar as áreas protegidas isoladas a um grande sistema (PRIMACK et al., 2001). Esta estratégia conservacionista facilita o fluxo de genes e a colonização permitindo que plantas e animais se dispersem de uma reserva para outra. Relatado por diversos autores, esse problema é algo recorrente já que apenas 2,2\% da área do cerrado estão incluídas em unidades de conservação de proteção integral (KLINK et al., 2005).

Embora grande parcela dos entrevistados dissera que sabiam ter conhecimentos a respeito dos fatores históricos do município e as principais causas da diminuição da estrutura populacional de Lobosguarás, os resultados chamaram muita atenção e preocupação em relação a preservação do animal embora alguns afirmarem desconhecer o termo 'extinção'.

Não obstante, apesar do pouco conhecimento da população entrevistada a respeito do termo extinção, $100 \%$ deles aderiram a algumas das alternativas como a conscientização da população referente à extinção do animal, a preservação do seu habitat e a inserção de projetos de conservação na região. Devido aos altos índices de remoção de cobertura vegetais, a criação de Unidades de conservação e o manejo adequado tornam-se cruciais na conservação de grandes carnívoros, como o Lobo-guará (LION, 2007). 
No Brasil existem em média 70 unidades de conservação com registros de Chrysocyon brachyurus, estando 4 localizada no estado do Tocantins, sendo três Parques Nacionais (PARNA Nascentes do Rio Parnaíba, PARNA do Araguaia, PARNA Serra Geral do Tocantins) e um Parque Estadual (do Jalapão) (PAULA et al., 2013).

O Plano de Ação Nacional-PAN, é no Brasil a principal iniciativa para conservação de espécies ameaçadas. O PAN Lobo-guará, foi criado pelo Centro Nacional de Pesquisa e Conservação de Mamíferos Carnívoros - CENAP, filiado ao Instituto Chico Mendes de Conservação da Biodiversidade - ICMBio, tem por objetivo a preservação desses canídeos, levantamento populacional e monitoramento da espécie (ICMBIO, 2009).

Machado et al. (2002) afirma que o Lobo-guará tem merecido atenção de muitos pesquisadores em relação à sua preservação. De acordo com todos os entrevistados, os estudos e o mapeamento do território do Chrysocyon brachyurus poderia ajudar a conhecer melhor seus hábitos alimentares e a convivência do Lobo-guará na nossa região, adotando medidas para sua preservação. Outra estratégia conservacionista seria o levantamento da quantidade ainda existente no local, áreas de forrageio, monitoramento da saúde das populações, estudos de variabilidade genética, tornando efetivo a fiscalização e monitoramento do animal, além dos trabalhos de Educação Ambiental nas escolas e comunidade como um todo.

\section{CONCLUSÃO}

Diante da percepção ambiental do presente trabalho, entende-se que apesar do Chrysocyon brachyurus (Lobo-guará) ser considerado um animal vulnerável, os resultados da pesquisa demostraram que a maioria da população tem um vasto conhecimento a respeito dos fatos históricos da ocorrência do animal e sua relação com a origem do nome do município de Guaraí (TO).

Contudo, atualmente observa-se que se perdeu muito ao longo do tempo a respeito das crendices populares, visto que os meios informativos fazem parte de todas as classes sociais, mesmo assim, ainda podese encontrar relatos negativos a respeito do Lobo-guará.

Tendo em vista os aspectos observados, constatou-se a necessidade do município de Guaraí criar uma Unidade de Conservação para conservar e fiscalizar a biodiversidade local incluindo o Lobo-guará neste processo. A inserção de programas de educação ambiental nas escolas e até mesmo nas zonas rurais tornase viável para que população possa ter conhecimento e mudança de atitude em relação a conservação dos ambientes naturais do município.

\section{REFERÊNCIAS}

AB'SÁBER, A. N.. Os domínios de natureza no Brasil: potencialidades paisagísticas. São Paulo: Ateliê, 2003.

ANIC, C. C.. Conhecimentos e crenças de algumas populações rurais do sudeste do Brasil frente ao loboguará, Chrysocyon brachyurus, Illiger, 1815, Mammalia: Canidae. Dissertação (Mestrado em Ciências) - Universidade de São Paulo, São Paulo, 2002.
ARRAIS, T. A.; CASTILHO, D.; NETO, O. P. A.. Integração nacional e fragmentação regional: o sentido territorial da BR-153 no centro-norte brasileiro. GEOgraphia, v.18, n.36, p.62-85, 2016

BOAS, A. H. V.; VENTURELLI, O. G.; OLIVEIRA, R. A.; CAMARGO, F. V.. Registro fotográfico do lobo-guará, Chrysocyon brachyurus (ILLIGER, 1815), em um fragmento 
de Mata Atlântica no Observatório Pico dos Dias, BrasópolisMG. Revista Brasileira de Zoociências, v.16, n.1-2-3, 2015.

IBGE. Instituto Brasileiro de Geografia e Estatística. Censo agropecuário 1970: Goiás. Rio de Janeiro: IBGE, 1970.

IBGE. Instituto Brasileiro de Geografia e Estatística. Censo agropecuário. Rio de Janeiro: IBGE, 2013.

IBGE. Instituto Brasileiro de Geografia e Estatísticas. Censo demográfico. Rio de Janeiro: IBGE, 2015.

ICMBIO. Instituto Chico Mendes de Conservação da Biodiversidade. Plano de Ação Nacional para a Conservação do Lobo-guará. 2009.

CARVALHO, C. T.. Dicionário dos mamíferos do Brasil. São Paulo: Fundação Parque Zoológico de São Paulo, 1979.

COSTA, H. M. A.; FREITAS, M. G.. Alguns helmintos parasitos do guará (Chrysocyon brachiurus (Illiger)) com a descrição de Molineus brachiurus n. sp. (Nematoda, Trichostrongylidae). Arquivos da Escola de Veterinária, v.19, p.25-29, 1967.

COUTINHO, L. M.. O conceito de bioma. Acta Botânica Brasílica, v.20, n.1, p.13-23, 2006.

CUNHA, N. R. D. S.; LIMA, J. E. D.; GOMES, M. F. D. M.; BRAGA, M. J.. A intensidade da exploração agropecuária como indicador da degradação ambiental na região dos Cerrados, Brasil. Revista de Economia e Sociologia Rural, v.46, n.2, p.291-323, 2008.

DAUZAT, A.. Les noms de lieux, origine et évolution. Paris: Librairie Delagrave, 1928.

DEWES, J. O.. Amostragem em bola de neve e respondentdrivensampling: uma descrição dos métodos. Monografia (Graduação) - Universidade Federal do Rio Grande do Sul, Porto Alegre, 2003.

DIEGUES, A. C. S.. Mitos e realidades sobre pescadores artesanais. IOUSP, 1988.

FARIA, N. O. D.. O bioma Cerrado e a extinção do Loboguará. Monografia (Licenciatura em Ciências Biológicas) Universidade de Brasília, Luziânia, 2013.

FERREIRA, J. C. V.. O Paraná e seus municípios. Maringá: Memória Brasileira. 1996.

GIORGI, A.. Phenomenology and psychological research. Pittburg: Duquesne University Press, 1986.

GOLDIM, J. R.; PITHAN, C. D. F.; OLIVEIRA, J. G. D.; RAYMUNDO, M. M.. O processo de consentimento livre e esclarecido em pesquisa: uma nova abordagem. Revista da Associação Médica Brasileira, São Paulo, v.49, n.4, p.372374, 2003.

GUARAÍ. Prefeitura Municipal de Guaraí. A Cidade. 2017.

HALUM, C.. Municípios Tocantinenses: suas origens, seus nomes. Provisão, 2008.

HÉBETTE, J.; ACEVEDO, R. E.. Mobilidade do trabalho e fronteira amazônica: a Belém-Brasília. 2015.
IBAMA.. Instituto Brasileiro do Meio Ambiente e Recursos Naturais Renováveis. Plano de Ação para Conservação do Lobo-guará: análise de viabilidade populacional e de habitat. Brasília: IBAMA, 2008.

IUCN. União Internacional para Conservação da Natureza. Red List of Threatenead Species. 2000.

KLINK, C. A.; MACHADO, R. B.. A conservação do Cerrado brasileiro. Megadiversidade, v.1, n.1, p.147-155, 2005.

KÖPPEN, W.. Climatologia. Cidade do México: Fundo de Cultura Econômica, 1931.

FERRAZ, S. T.; LEONARDI, V.. Os historiadores e os rios: natureza e ruína na Amazônia brasileira. Brasília: EdUNB, 1999.

LION, M. B.. Diversidade genética e conservação do loboguará, Chrysocyon brachyurus, em áreas protegidas do Distrito Federal. Dissertação (Mestrado em Ecologia) Universidade de Brasília, Brasília. 2007.

MACHADO, A. B. M., DRUMMOND, G. M.; PAGLIA, A. P.. Livro vermelho da fauna brasileira ameaçada de extinção. In: MMA. Livro vermelho da fauna brasileira ameaçada de extinção. Brasília: Fundação Biodiversitas, 2008.

MACHADO, G. V.; FONSECA, C. C.; NEVES, M. T. D.; PAULA, T. A. R.; BENJAMIN, L. A.. Topografia do cone medular no loboguará (Chrysocyon brachyurus Illiger, 1815). Revista brasileira de ciência veterinária, v.9, n.2, 2002.

MACHADO, L. O.. Urbanização e política de integração no norte de Goiás. Dissertação (Mestrado em Geografia) Universidade Federal do Rio de Janeiro, Rio de Janeiro, 1979.

MAIA, O. B.; GOUVEIA, A. M. G. Birth and mortality of maned wolves Chrysocyon brachyurus (Illiger, 1811) in captivity. Brazilian Journal of Biology, v.62, n.1, p.25-32, 2002.

MANTOVANI, J. E.; MATTOS, P. R.; SANTOS, J. E.; PIRES, J. R. Sensoriamento remoto e radiotelemetria no estudo de padrões de uso da paisagem pelo lobo-guará no interior do estado de São Paulo. In: SIMPÓSIO BRASILEIRO DE SENSORIAMENTO REMOTO, 13. Anais. Florianópolis, 2007.

MARCONI, M. A.; LAKATOS, E. M.. Metodologia científica. São Paulo: Atlas, 2004.

MELO, P. A. G.. Toponímia indígena: um estudo lexical dos nomes de municípios alagoanos de étimo tupi. Veredas, v.6, n.1, p.160-179, 2013.

MESQUITA, E. D. S.. Percepções e usos da fauna silvestre pelas comunidades humanas do entorno da Reserva Particular do Patrimônio Natural do Caraca, Catas Altas/Santa Barbara, MG. Dissertação (Mestrado em Zoologia dos Vertebrados) - Pontifícia Universidade Católica, Belo Horizonte, 2004.

MOYSÉS, G. L. R.; MOORI, R. G.. Coleta de dados para a pesquisa acadêmica: um estudo sobre a elaboração, a validação e a aplicação eletrônica de questionário. In: 
ENCONTRO NACIONAL DE ENGENHARIA DE PRODUÇÃO, 27. Anais. 2007.

NAVARRO, E. A.. Método moderno de Tupi antigo: a língua do Brasil dos primeiros séculos. São Paulo: Global, 2006.

OLIVEIRA A. G. M.; KAZAMA, R.. Percepção ambiental de visitantes do Zoo de Brasília e a possibilidade de se aprender e ensinar nesse ambiente. Acta Scientiarum: Human and Social Sciences, v.36, n.1, 2014.

OTTO, R. O.. Sagrado: os aspectos irracionais na noção de divino e sua relação com o irracional. Petrópolis: Vozes, 2007.

PAULA, R. D.; RODRIGUES, F. H. G.; QUEIROLO, R. J.D.; LEMOS, F.; RODRIGUES, L.. Avaliação do risco de extinção do lobo-guará Chrysocyon brachyurus (Illiger, 1815) no Brasil. Biodiversidade Brasileira, n.1, p.146-159, 2013.

PAULA, R. C.; MEDICI, P.; MORATO, R. G.. Plano de Ação para a Conservação do Lobo-Guará-Análise de Viabilidade Populacional e de Habitat. Brasília: ICMBio, 2008.

PRIMACK, R. B.; RODRIGUES, E.. Biologia da conservação e diversidade biológica. In: PRIMACK, R. B.; RODRIGUES, E.. Biologia da Conservação. Londrina: Vida, 2001.

RIBEIRO, J. F.; OLIVEIRA, M. C.; GULIAS, A. P. S. M.; FAGG, J. M. F.; GOIS AQUINO, F.. Usos Múltiplos da Biodiversidade no Bioma Cerrado: estratégia sustentável para a sociedade, 0 agronegócio e os recursos naturais. In: Savanas: desafios e estratégias para o equilíbrio entre sociedade, agronegócio e recursos naturais. Planaltina: Embrapa Cerrados, 2008. p.337-360
RODRIGUES, W. C.. Metodologia científica. Paracambi: FAETEC/IST, 2007.

ROSTAING, C.. Les noms de Lieux. Paris: Presses Universitaires de France, 1961.

SADALA, M. L. A.. A fenomenologia como método para investigar a experiência vivida: uma perspectiva do pensamento de Husserl e de Merleau-Ponty. In: SEMINÁRIO INTERNACIONAL DE PESQUISA E ESTUDOS QUALITATIVOS, 2. Anais. Bauru: Universidade do Sagrado Coração de Jesus; Sociedade de Estudos e Pesquisa Qualitativa, 2004.

SILVA, J.; STRAHL, S.. Usos folclóricos de la fauna silvestre en nueve parques nacionales al norte de Venezuela. Vida Silvestre Neotropical, v.3, n.2, p.100-107, 1994.

SOUSA, L. R.. Chrysocyon brachyurus: ecologia e comportamento do Lobo-guará. Monografia (Licenciatura em Ciências Biológicas) - Centro Universitário de Brasília, Brasília, 2000.

STRAUBE, F. C.. Guará: origem histórica do vocábulo e formação de alguns topônimos paranaenses. Boletim do Instituto Histórico e Geográfico do Paraná, v.50, p.91-100, 1999.

TERBORGH, J.. Maintenance of diversity in tropical forests. Biotropica, v.24, n.2, p.283-292, 1992.

WHYTE, A. V. T.. Guidelines for fields studies in environmental perception. Paris: UNESCO, 1977.

A CBPC - Companhia Brasileira de Produção Científica (CNPJ: 11.221.422/0001-03) detém os direitos materiais desta publicação. Os direitos referem-se à publicação do trabalho em qualquer parte do mundo, incluindo os direitos às renovações, expansões e disseminações da contribuição, bem como outros direitos subsidiários. Todos os trabalhos publicados eletronicamente poderão posteriormente ser publicados em coletâneas impressas sob coordenação da Sapientiae Publishing, da Companhia Brasileira de Produção Científica e seus parceiros autorizados. Os (as) autores (as) preservam os direitos autorais, mas não têm permissão para a publicação da contribuição em outro meio, impresso ou digital, em português ou em tradução. 